\title{
Exploration on Moral Education Function in Traditional Opera
}

\author{
Hongxin Ren
}

Music School, Shaanxi Normal University, Xi'an, 710119, China

\author{
Keywords: Traditional opera; Moral education; Function
}

\begin{abstract}
As an important part of Chinese traditional culture, the traditional opera influences generations of Chinese people; it is indisputable that the traditional opera has certain social function, but the research on its moral education function has certain limitations, and the research is also not deep. The exploration on moral education function in traditional opera plays an important role in promoting social ideological and moral education, and the moral education is also an important part of socialist ideological and cultural construction. This paper mainly analyzes the moral education function in traditional opera.
\end{abstract}

\section{Introduction}

The traditional opera is an important part of Chinese traditional culture, and it is characterized by wide coverage, deep psychological influence, and rich cultural information, etc.; however, it plays a special role in the culture. The traditional opera is neither as elegant as poetry nor plays an important role in history; due to its uniqueness, it plays an irreplaceable function. The most outstanding function is the moral education function which has been acknowledged as early as in ancient time; the high-platform education is ancient scholars' evaluation on traditional opera, but the research on its education function is superficial, with certain limitations.

\section{Overview of Chinese traditional opera}

Chinese traditional opera is an important part of Chinese traditional culture, and also an important Chinese artistic form; watching traditional opera is also a kind of way of leisure that most of people like. Furthermore, Chinese traditional opera exists in world opera circle in a unique posture. The origin of Chinese traditional opera can date back to primitive society; at that time, the opera is shown in a form of song and dance; however, from perspective of overall development history of opera, its development is very slow, and Chinese opera system is formed through long-time perfection. The traditional opera forms on the basis of talking-singing arts, folk song and dance, and humorous performance; from Western Han and Eastern Han Dynasties to two Song Dynasties, the traditional opera experiences folk opera, joining-the-arm opera, and some folk skills are added, such as acrobatics, skills in Wushu, and dance; after the integration, Chinese tradition opera is basically formed. The way of singing of opera is produced based on way of singing of folk music and folk songs, the performance ways include singing, dancing, musical dialogues, martial arts, and the character roles include man's role, woman's role, painted face, introductory role, clown. The traditional opera is popular in folk and court; it enriches people's life and causes an important influence on people's life, and many people are also willing to imitate various kinds of character roles.

According to the survey, there are 317 types of Chinese opera, including more than 10,000 kinds of traditional theatrical pieces. The widely known types of opera include Beijing opera, Shaoxing opera, Jin opera, Kunqu opera, Shangdang clapper, Shanxi opera, Huangmei opera, Sichuan opera, and flower drum opera, and the most popular opera is Beijing opera. The traditional opera also contains many Chinese philosophic thoughts, which are shown via performance as the reflection of Chinese traditional aesthetics. Besides, the traditional opera includes many novels, verses, ditties, odes and songs, and its rich connotation can't be replaced by other artistic form. 


\section{Social functions of traditional opera}

\section{Function of cultural inheritance}

As an important part of Chinese traditional culture, the traditional opera contains the humanistic spirit of Chinese traditional culture and also stands for Chinese spiritual culture; it is the key for Chinese traditional cultural inheritance.

\section{Function of enriching spiritual culture}

Chinese traditional opera has a long history, and many classical operas are always performed; the main reason is that the traditional opera mainly comes from people and then becomes popular among people; it can be said that the traditional opera is the reflection of folk art, with extremely wide mass base. People's pleasure, anger, sorrow, and joy can be shown in opera, thus many people like opera and tell "their stories" to later generations through opera, which plays an educating function. People can enjoy the satisfaction of spiritual world from opera, thus the traditional opera plays a function in enriching spiritual culture.

\section{Function of social stability}

Many excellent works in traditional opera are not only artistic, but also have high ideological level, and they are also of great realistic significance in contemporary era; this is also the reason why the traditional opera is long lasting. The moral function of traditional opera is acknowledged by wide people, for the opera reflects people's behavioral habit, especially reflects Chinese national spiritual quality; for example, the Chinese traditional virtues such as loyalty and filial piety are reflected in opera, which can play a moral education function for later generations, make everyone in the society filial to their parents and loyal to their country, and promote social stability; this is also suitable to the concept of contemporary harmonious society. Therefore, as for modern society, the traditional opera is of important realistic significance.

\section{Analysis on moral education function in traditional opera}

As one of important way of cultural inheritance, the traditional opera contains rich connotation; in particular, it has moral education function and it is of important realistic significance. The analysis on moral education function in traditional opera is also of great significance.

The culture dominates morality, and the opera has moral education function.

In Chinese ancient society, the common people rarely have chance to learn in school; as for wide people, the only chance to accept education is to enjoy opera from which people can obtain much knowledge, know the story about previous generation, and know the history; meanwhile, the opera is also a way through which the governor governs people and carry out spiritual control. The opera contains many excellent virtues and can exert influence on people. Now that people can't accept the education in school, how do people understand so many classic works? Watching the opera is just one way; for example, Chinese people all know four great classical novels, and the opera, as a kind of specific form of textbook, plays an important role in people's life. The cultural transmission in ancient society also depend on traditional opera. The governors reflect their thoughts through opera so that it is easier for people to accept those thoughts; as for abstract ideology and culture, it is hard for people to accept them, and then the opera is used as a kind of thought tool to deliver ideology and culture to people. The traditional opera reflects Chinese cultural thoughts, aesthetic opinions, moral sentiment, spiritual mentality, and national customs; meanwhile, due to influence by traditional opera, the changes also happen in those spirits and changes.

The social being determines social consciousness. As a part of social ideology, the culture carries the education function; however, as a kind of culture, the opera also has certain education function. The opera originally comes from people; while it becomes a moral education tool used by governors, it is added with "noble quality", thus the opera realizes the transition from vulgarity to elegance and it is reflected via mainstream ideology. For example, in Ming Dynasty, Zhu Yuanzhang placed the 
opera The Story of Pipa at a position equal to Four Books and Five Classics, and integrated governor's consciousness into the opera. In ancient China, different dynasties all use the opera as the moral education tool to govern wide people. In addition, the governors also make clear stipulations for performance range of opera; the opera related to some thoughts such as loyalty and filial piety is allowed to be performed, but the opera which damages their respect or contains rebellious thought is not allowed and will be punished. Therefore, the opera authors shall conform to the governors' requirement to remove adverse factor to carry out opera compiling, and regard the opera creation as a kind of moral education tool. Therefore, the opera has strong ethical feature. For example, the opera Gather Firewood and Teach Young Brother is an opera which educates people how to be an elder brother, the opera Chen Shimei and Qin Xianglian is an opera which educates people how to be a servant, and the opera Ode to Shadow is an opera which educates people how to be a wife. There are also many operas related to Buddhist content to spread feudal filial piety; meanwhile, some operas contain Confucian thoughts, but they merely emphasize the dissemination of ideas and ignore the artistic feature of opera.

As a kind of popular cultural activity, the traditional opera plays an important role in enriching people's life; restricted by economic condition, people commonly lack of spiritual life, thus enjoying the opera becomes an important way of entertainment. The traditional opera always spreads social mainstream value; as for those profound articles and thoughts which can't be easily accepted, while they are shown via opera, it is able to realize good effect, let people accept them, and influence people's moral ideas; through opera, people can see what behaviors are correct and what kind of life is beautiful, which reflects the cultural function of traditional opera.

\section{Function of moral inheritance}

The mainstream culture in Chinese traditional culture is Confucian culture, and another one is folk culture, both of which form Chinese traditional culture, collide, blend and promote each other. As a kind of folk culture, the opera is typical and it is an important part of people's entertainment life. The traditional opera's audiences are mainly farmers and citizens, and the operas' authors also have humble status; meanwhile, people who engage in opera industry also means people with humble status. Therefore, the opera always shows hardships of the people and folk value. Although the opera is controlled by governors and many works which conform to governors' thoughts appear, some works which reflect common people's life also appears among the people.

In the transition process of opera from vulgarity to elegance, in order to be accepted by people and obtain more audiences, the governors have to penetrate some folk consciousness into opera so that the people can accept the opera; therefore, many operas show folk ethical view and outlook of right and wrong; through describing the figures in opera, it is able to let people distinguish what is right or wrong and let them have the feeling of clear-cut stand on what to love and what to hate. Meanwhile, the traditional opera often includes complicated legal case opera whose performance can put forward moral concept, satirize corruption through misuse of law, praise virtue and punish vice, shape figures through vivid image, and even endow with exaggerated method to exaggerate loyal and filial people as well as wicked people so that people can clearly know good and evil. Instead of stiff education, those operas can be easily accepted and understood by people, thus they can directly influence people's moral concept and value concept. As for figure modeling in opera, the spirit reflected by the figures is imitated by people so as to realize the internalization of moral concept.

Besides, in traditional opera, there are also many special consciousnesses and values which express people's longing for realistic life, but this causes some influence on the stability of social order; however, this also reflects people's helplessness in changing the reality, thus people can only meet spiritual demand and express their mood via opera works.

\section{Curing function of traditional opera}

Currently, the reason why the social regulation can be smoothly implemented in maintaining public security and guaranteeing various productions is that it can restrain people's desire and reduce various kinds of bad things caused by impulsion under the condition of no-clear-headed state, as well as transform people's inner desire into the goal they want to complete, propose the method of realizing the goal, and then reduce the disorderly conduct caused by desire. 
China always follows legitimate thought, and such kind of legitimate thought can help the governors to realize their goal and adapt to governance demand, and it is realized on the basis of restricting the morality, thus various kinds of desires in our life all reflect the restraint thoughts to different degree. As for those desires and morality which have been restricted by social regulations for a long time, if we can't adopt effective means to make guidance, people's inner heart will be under imbalanced state of restraint which becomes a kind of negative energy. While those accumulated emotions are relieved, the rational force is very powerful and there will be large damage on the society; if the external environment is not suitable to carry out the guidance, this bad emotion will continuously accumulate in people's heart and then cause spiritual barrier and disease. Therefore, as for people living in autocratic society, the correct psychological counseling and communication are very important; if such kind of psychological problem can't be correctly guided, the whole society will fall into disorderly state. In Chinese traditional opera, various factors mutually co-exist and work as well as reflect different feeling in performance atmosphere.

Chinese traditional opera pays great attention to its entertainment function; in early opera, the most important function is entertainment function. It is especially obvious in opera script; the comic part is common part, and even many comic parts are not related to the story of opera. It seems that the bantering becomes a decoration to the opera. In Yuan Opera in Yuan Dynasty and opera in Ming and Qing Dynasty, the clown often plays a function of amusement, thus people can effectively relieve the repression in their life. Up to now, in grass-root people's life, we can still see the amusing and joking scene in opera, and it seems that they become an indispensable entertainment in people's life.

\section{Conclusion}

In conclusion, the traditional opera shows the moral education function. In ancient society, the opera is not only a part of people's cultural life, but also a tool used by the governors to carry out spiritual governance. However, we must see the inheritance of traditional opera on Chinese traditional culture, and clearly know the important function of traditional opera in people's life, as well as fully know the function of traditional opera on society and deeply analyze the moral education function of moral opera. In current society, the traditional opera is still an important part of people's entertainment life and puts forward Chinese traditional culture; it plays an important function in later generations' inheriting Chinese traditional culture, and also plays the ideological and moral education function, thus it is of important realistic significance.

\section{References}

[1] Yu Xiaoyao, Start from Modernization of Traditional Opera to Realize Step-out of Chinese Operas: take Kunqu opera as an example --- comparison on foreign exchange of new concept Kunqu opera Zang and youth version Mudanshi, Hundred Schools In Art, 2013 (2): 208-210.

[2] Ma Wenying, Liu Jinliang, Analysis on Cultural Ecology of Traditional Opera - take the rise and decline of north Anhui local opera as an example, Journal of Shaoguan University, 2013, 34 (9): 149-152.

[3] Ma Yuyu, Discussion on Dissemination and Influence of Traditional Opera in Students under View of Mass Media, Home Drama, 2014 (8): 19-19.

[4] Zhang Jing, Application of Traditional Opera Art in Vocational Music Education, Music Magazine, 2014 (12):78-78.

[5] Yuan Xian, Research on Era Significance of Traditional Opera Culture Education for Adolescents, Popular Art, 2013(24):225-226.D. 